\title{
Poly-lysine/cyclodextrin polymer-MWCNTs as a Selective Sensing Platform for Hydroquinone and Catechol Simultaneous Determination
}

\author{
Qian Han", Kangkang He, Ruisheng Han, Jianda Zhang
}

Laboratory of Environment change and Ecological Construction of Hebei Province, College of Resources and Environment Science, Hebei Normal University, Shijiazhuang, Hebei 050024, PR China.

*E-mail: hanq@mail.hebtu.edu.cn

doi: $10.20964 / 2017.07 .68$

Received: 28 March 2017 / Accepted: 14 May 2017 / Published: 12 June 2017

Electropolymerization of L-lysine incorporating multiwall carbon nanotubes (MWCNTs) dispersed in $\beta$-cyclodextrin prepolymer (CDP) solution was constructed a very efficient sensor. Scanning electron microscopy was employed to characterize the surface morphology of the modified electrode. The proposed sensor excellently enhanced the selectivity in the simultaneous determination of HQ and CC by differential pulse voltammetry and cyclic voltammetry. Comparing with bare GCE, MWCNTs/GCE, CDP-MWCNTs/GCE, the introduction of L-lysine polymer film effectively declined the shoulder peak of buffer soultion which seriously interfered the dection of hydroquinone (HQ) and catechol (CC) isomers. The PLL/CDP-MWCNTs/GCE displayed good discrimination ability and high sensitivity toward HQ and CC, peak-to-peak separation about $105 \mathrm{mV}$ were obtained. The linear response range for hydroquinone and catechol were $0.1 \mu \mathrm{M}-100 \mu \mathrm{M}$. The detection limits of HQ and CC were $0.044 \mu \mathrm{M}, 0.058 \mu \mathrm{M}$, respectively.

Keywords: Hydroquinone; Catechol; L-lysine polymer; Multiwall carbon nanotubes; $\beta$-Cyclodextrin prepolymer; Electrochemical behavior

\section{$\underline{\text { FULL TEXT }}$}

(C) 2017 The Authors. Published by ESG (www.electrochemsci.org). This article is an open access article distributed under the terms and conditions of the Creative Commons Attribution license (http://creativecommons.org/licenses/by/4.0/). 